\title{
ACC-derived Ethylene Production, a Sensitive Test for Seed Vigor
}

\author{
Anwar A. Khan \\ Department of Horticultural Sciences, New York State Agricultural Experiment Station, Cornell University, \\ Geneva, NY 14456
}

Additional index words. accelerated aging, natural aging, seed deterioration, vigor test, ethylene-forming enzyme, 1aminocyclopropane-1-carboxylic acid (ACC), seed quality, seed performance

\begin{abstract}
ACC-derived ethylene production was used as an index of seed vigor of lettuce (Lactuca sativa $\mathbf{L}$.), cabbage [Brassica oleracea (Capitata Group)], tomato (Lycopersicon esculentum Mill.), snap bean (Phaseolus vulgaris L.), and sweet corn (Zea mays L.) seeds. Seeds were aged at $40 \mathrm{C}$ and $93 \%$ relative humidity over saturated solution of $\mathrm{KH}_{2} \mathrm{PO}_{4}$ for various times to obtain seeds of differing vigor. Naturally aged lettuce seeds, differing in vigor, were also used. Depending on the seed type, 0.25 to $2 \mathrm{~mm}$ ACC (saturating dose) was needed to produce maximal amounts of ethylene. Seeds in the presence of ACC produced a much larger amount of ethylene than those in the absence of ACC, the ACC-derived ethylene could be detected before germination, and ACC had no adverse effect on germination. ACC-derived ethylene production paralleled vigor loss as determined by a decrease in percentage germination over a soak period required for complete germination of nonaged seeds (16 hours for lettuce, 24 hours for cabbage, and 48 hours for tomato and sweet corn), an increase in mean germination time (determined for lettuce only), and a decrease in seedling growth (determined for snap bean only). Second degree polynomial and logarithmic equations generated for the relationship of ACC-derived ethylene production to germination or growth parameters following seed aging, provided good to excellent fit. As a vigor test, the ACC-ethylene procedure has several advantages over the non-ACC ethylene procedure: It improves the sensitivity of the test by enhancing ethylene production, permits detection of small differences in vigor, and allows detection of ethylene before germination within a few hours of soaking. Chemical name used: 1-aminocyclopropane-1-carboxylic acid (ACC).
\end{abstract}

Loss of seed vigor is a result of physical and biochemical changes and is accelerated under adverse conditions (e.g., high humidity and high temperature). Numerous attempts have been made to develop rapid and reliable tests to accurately monitor vigor changes during storage and to correctly predict the planting value of seeds. Some of the widely used tests are the speed of germination (Toole et al., 1948), the cold test (Clark, 1954), the accelerated aging test (Byrd and Delouche, 1971), and the tetrazolium (TZ) test (Moore, 1976).

Other changes that have been correlated with seed deterioration, and are potentially useful vigor tests, include degradation of ribosomes and ribonucleic acid (RNA) (Roberts et al., 1973; VanOnckelen et al., 1974), reduced ability to synthesize proteins and RNA (Osborne et al., 1974; VanOnckelen et al., 1974), loss of ATP (Ching, 1982; VanOnckelen at al., 1974), and solute leakage (Matthews and Bradnock, 1968).

Volatiles produced during seed soak have also been used as a measure of seed vigor. Aldehydes and alcohol produced by peas and soybean seeds were negatively correlated with aging (Harman et al., 1982; Woodstock and Taylorson, 1981). On the other hand, ethylene production was positively correlated with seed vigor in leek and snap beans (Samimy and Taylor, 1983; Takayanagi and Harrington, 1971).

Many seeds, including snap bean and leek, produce barely detectable levels of ethylene at the time of germination ( Gorecki et al., 1991; Khan et al., 1987, Prusinski and Khan, 1990; Samimy and Taylor, 1983; Takayanagi and Harrington, 1971). As the seeds age, their ethylene-producing capacity decreases even further, making ethylene a poor marker for scoring seed vigor classes. We previously reported that the ability of rice seeds to produce ethylene following germination was greatly enhanced by adding

Received for publication 27 Jan. 1994. Accepted for publication 13 Apr. 1994. The cost of publishing this paper was defrayed in part by the payment of page charges. Under postal regulations, this paper therefore must be hereby marked advertisement solely to indicate this fact.
ACC during soaking and the ACC-derived ethylene correlated well with seed vigor as determined by seedling growth (Khan and Seshu, 1987). In a recent study, pea and cocklebur seeds of differing vigor, soaked previously in water for 20 and $32 \mathrm{~h}$, produced ethylene upon addition of ACC that paralleled seed vigor (Gorecki et al., 1991). The conversion of ACC to ethylene is mediated by the ethylene forming enzyme (EFE) or ACC oxidase (Yang, 1985).

The objectives of this study were to 1) ascertain if the use of ACC during seed soak would permit ethylene to be detected before actual germination (radicle protrusion), 2) investigate the suitability of the ACC-derived ethylene as a reliable and sensitive test for seed vigor, and 3) extend the applicability of the test to diverse seeds types.

\section{Materials and Methods}

Freshly harvested (1-to 2-year-old) seeds of lettuce 'Mesa 659', tomato 'Super Marmande', cabbage 'King Cole', snap bean 'BBL 47', and sweet corn 'Challenger' were obtained from seed companies. All seeds were stored at $7 \mathrm{C}$ and $28 \%$ relative humidity (RH) until used. In addition, seven seed lots of 'Mesa 659' lettuce, stored in glass bottles at $5 \mathrm{C}$ and ambient RH and at $7 \mathrm{C}$ and $28 \% \mathrm{RH}$ over periods ranging from 3 to 20 years and differing in vigor (based on speed of germination), were used, and are referred to as naturally aged seeds.

For accelerated or rapid aging, seeds were kept for different times at $40 \mathrm{C}$ and $93 \% \mathrm{RH}$ in 4-liter desiccators over a saturated solution of $\mathrm{KH}_{2} \mathrm{PO}_{4}$ in 9-cm petri plates, with lids raised with wire supports so as to create a 2.5 -cm opening for free exchange of water vapor. Nonaged and aged seeds, in three replicates of 50 (lettuce, cabbage, and tomato) or 15 (sweet corn) seeds each, were soaked at $25 \mathrm{C}$ in $5-\mathrm{cm}$ (lettuce, cabbage, and tomato) or 9-cm (sweet corn) petri plates, lined with two layers of Whatman no. 1 filter paper and moistened with $3(5-\mathrm{cm}$ plate) and $10 \mathrm{ml}(9-\mathrm{cm}$ plate) water or ACC solution. Germination (seeds with visible radicles, usually 1 

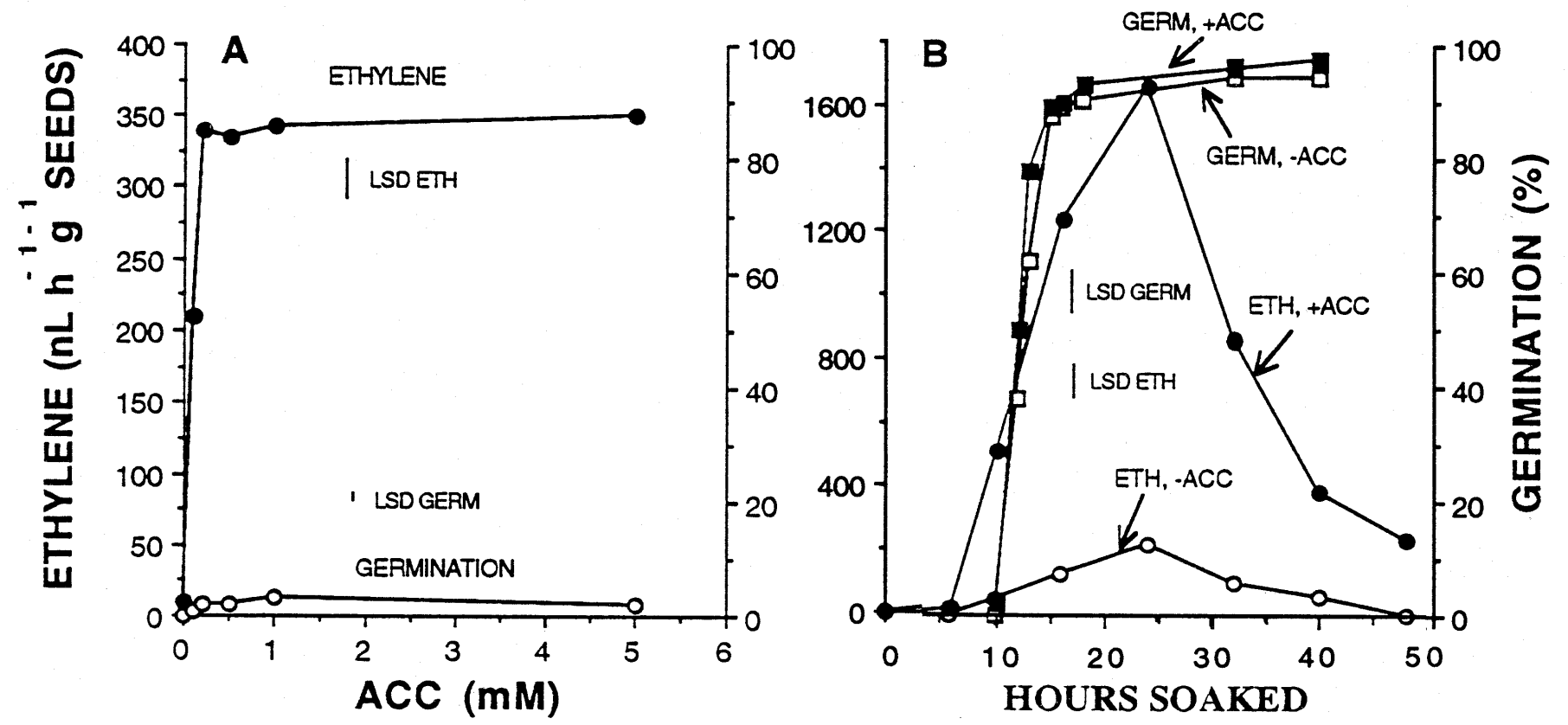

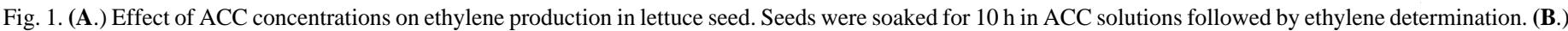
Time course of ethylene (ETH) production and germination (GERM) in lettuce seed in presence $(+)$ and absence $(-)$ of $1 \mathrm{~mm} \mathrm{ACC}$ Bars denote $\mathrm{LSD}_{0.05}$.

to $2 \mathrm{~mm}$ in length) counts were made frequently, and germinated seeds removed.

The ability of nonaged seeds to fully germinate $(>90 \%)$ in the shortest period of time (a measure of speed of germination) was used as an index of seed vigor (Association of Official Seed Analysts, 1993). This period was $16 \mathrm{~h}$ for lettuce, $24 \mathrm{~h}$ for cabbage, and $48 \mathrm{~h}$ for tomato and sweet corn seeds. Mean germination time (MGT), calculated for rapidly and naturally aged lettuce seeds, refers to time required for $50 \%$ of final germination, and was used as a measure of speed of germination or seed vigor.

Snap bean seeds (in three replicates of 25 seeds each) of differing vigor, were sown on a layer of moist $27 \times 90-\mathrm{cm}$ germination paper (Anchor paper, Packaging Converter, Hudson, Wis.), 4 and $12 \mathrm{~cm}$ from the upper and lower edges, covered with another layer of moist paper, rolled, and placed in a vertical position in 4-liter beakers containing 0.5 liters water at $25 \mathrm{C}$ in continuous light. Germination counts and seedling length (root plus hypocotyl) were made after a 90-h soak. Seedling growth as a measure of seed vigor [based on per seed planted (nongerminated seeds had zero hypocotyl plus root growth)], was used only for snap bean seeds.

For ethylene determination, nonaged or aged lettuce, cabbage, and tomato seeds, in three replicates of $0.5 \mathrm{~g}$ seeds each, were soaked for varying periods on filter paper moistened with $3 \mathrm{ml}$ water or ACC solution in 5-cm petri plates. Sweet corn and snap bean seeds in three replicates of 15 and 10, respectively, were soaked for $10 \mathrm{~h}$ at $25 \mathrm{C}$ in light on filter paper moistened with $10 \mathrm{ml}$ water or ACC solution. After soaking, seeds were wipe-dried on paper towels and transferred to 28-ml (sweet corn and snap bean) or 5.7-ml (lettuce, tomato, and cabbage) glass tubes. In a separate study, 50 slit (seeds were slit by making a vertical cut extending one-third the length of the seeds) and intact lettuce seeds were soaked for various times in 5-cm petri plates lined with two layers of filter paper (Whatman No. 1) and moistened with $3 \mathrm{ml}$ water or ACC solution, wipe-dried, and transferred to 5.7-ml tubes. After incubation for $1 \mathrm{~h}$ at $25 \mathrm{C}$ in light, ethylene content in the gas phase of the tube was determined as described before (Khan and Prusinski,
1989). One-ml gas samples were withdrawn with a gas-tight syringe and injected into a gas chromatograph (5890 Series II; Hewlett-Packard, Rockville, Md.) equipped with a flame-ionization detector and a $183 \times 0.32-\mathrm{cm}$ stainless steel column containing Poropak Q.

Data on percentage germination, growth, and ethylene production were analyzed using analysis of variance (ANOVA) and LSD. Appropriate regression equations were generated and fitted to the experimental data using the procedures of PC-SAS (SAS Institute, 1985).

\section{Results}

Lettuce. Lettuce seeds produced measurable amounts of ethylene only at the beginning of germination at about $10 \mathrm{~h}$. These amounts were low, but were greatly enhanced when ACC was applied to seed during this period. At $0.25 \mathrm{~mm}$, ACC saturated the system as higher concentrations did not increase ethylene production (Fig. 1A). Ethylene production peaked at $24 \mathrm{~h}$ of soaking and then declined (Fig. 1B). Addition of ACC had no adverse effect on germination of seeds. A much larger amount of ethylene was produced in the presence or absence of ACC when seeds were slit at the cotyledonary end (Fig. 2). Measurable amounts of ethylene were found after as little as $0.5 \mathrm{~h}$ of soaking in slit seeds and in 4 $h$ in intact seeds in the presence of ACC. In the absence of ACC, ethylene was not detected in intact seeds during the 8-h soak.

The enhanced ability of the seeds to produce ethylene before germination in the presence of ACC was utilized to score seeds of various aged classes or of differing vigor. The ACC-derived ethylene (determined after seeds were soaked for $8 \mathrm{~h}$ ) decreased in parallel with germination (determined after seeds were soaked for $16 \mathrm{~h}$ ) of rapidly aged seeds (Fig. 3A). Addition of ACC had little effect on germination. Also, the MGT increased as ethylene production decreased in rapidly aged seeds (Fig. 3B). As in the case of rapidly aged seeds, MGT of naturally aged seeds also increased as ethylene production decreased. Ethylene production was highly correlated with germination percentage and MGT of 
both rapidly aged and naturally aged seeds. A second-degree polynomial and logarithmic equations generated for the curvilinear relationships of percentage germination to ethylene production and of MGT to ethylene production, respectively, provided the best fit for the experimental data (Fig. 4 A and B).

Cabbage. In the absence of ACC, cabbage seeds produced no detectable ethylene before germination. Only small amounts of ethylene were detected after germination at $20 \mathrm{~h}$ (Fig. 5A). Addi-

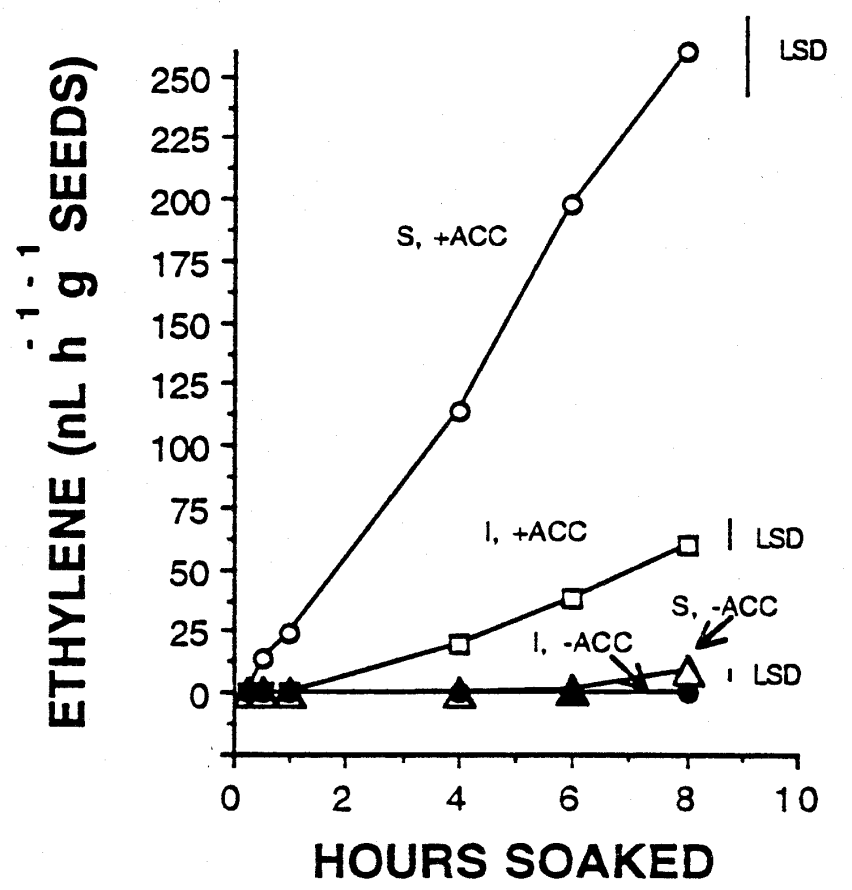

Fig. 2. Ethylene production by intact (I) and slit (S) lettuce seeds soaked in the presence (+) and absence (-) of $1 \mathrm{~mm}$ ACC for 0 to $8 \mathrm{~h}$. Bars adjacent to the curves denote $\operatorname{LSD}_{0.05}$. tion of $1 \mathrm{~mm}$ ACC (a saturating dose) greatly enhanced the ethylene production before or after germination and even promoted germination to some extent. Aging reduced the germination percentages (in both presence and absence of ACC) and the ACC-derived ethylene production in a parallel fashion(Fig. 5B). The ACC-derived ethylene production was curvilinearly related to germination, regardless of the presence or absence of ACC, and a quadratic equation provided an excellent fit for the experimental data (Fig. 6).

Tomato. Nonaged tomato seeds produced a measurable amount of ethylene in $1 \mathrm{~mm}$ ACC (a saturating dose) at $30 \mathrm{~h}$ of soaking before germination. In the absence of ACC, no ethylene was produced before germination and it took $48 \mathrm{~h}$ to produce an amount comparable to that in the presence of ACC (Fig. 7A). Ethylene produced at $48 \mathrm{~h}$ was 8 -fold greater in the presence than in the absence of ACC. Addition of ACC had little effect on germination. Aging decreased the ACC-derived ethylene production (determined after a 30-h soak) and germination (determined after a 48$\mathrm{h}$ soak) in a parallel fashion (Fig. 7B). A quadratic equation provided an excellent fit for the relationship of ethylene production to germination (Fig. 8).

Snap bean. Preliminary studies showed that these seeds produced no detectable amounts of ethylene before germination at 20 to $22 \mathrm{~h}$ (not shown). Addition of $1 \mathrm{~mm}$ ACC (a saturating dose) had little effect on germination but permitted detection of ethylene even at 8 to $10 \mathrm{~h}$ of soaking (the level of ethylene at $10 \mathrm{~h}$ of soaking was $4 \mathrm{nl} \cdot \mathrm{h}^{-1} \cdot \mathrm{g}^{-1}$ seeds). The ACC-derived ethylene produced after a 10-h soak of snap bean seeds correlated well with percentage germination (Fig. 9A) and with seedling shoot length (Fig. 9B) after a 90-h soak. Aging 1 to 3 days enhanced seed vigor (as shown by improved seedling growth) and ethylene production; with further increase in aging period, there was a decrease in ethylene production and germination. Quadratic equations provided good to excellent fit for the relationship of germination to ethylene production $\left(R^{2}=0.78\right)$ and of seedling growth to ethylene production $\left(R^{2}=0.91\right)$, respectively (Fig. 10).

Sweet corn. No ethylene was detected in sweet corn seeds
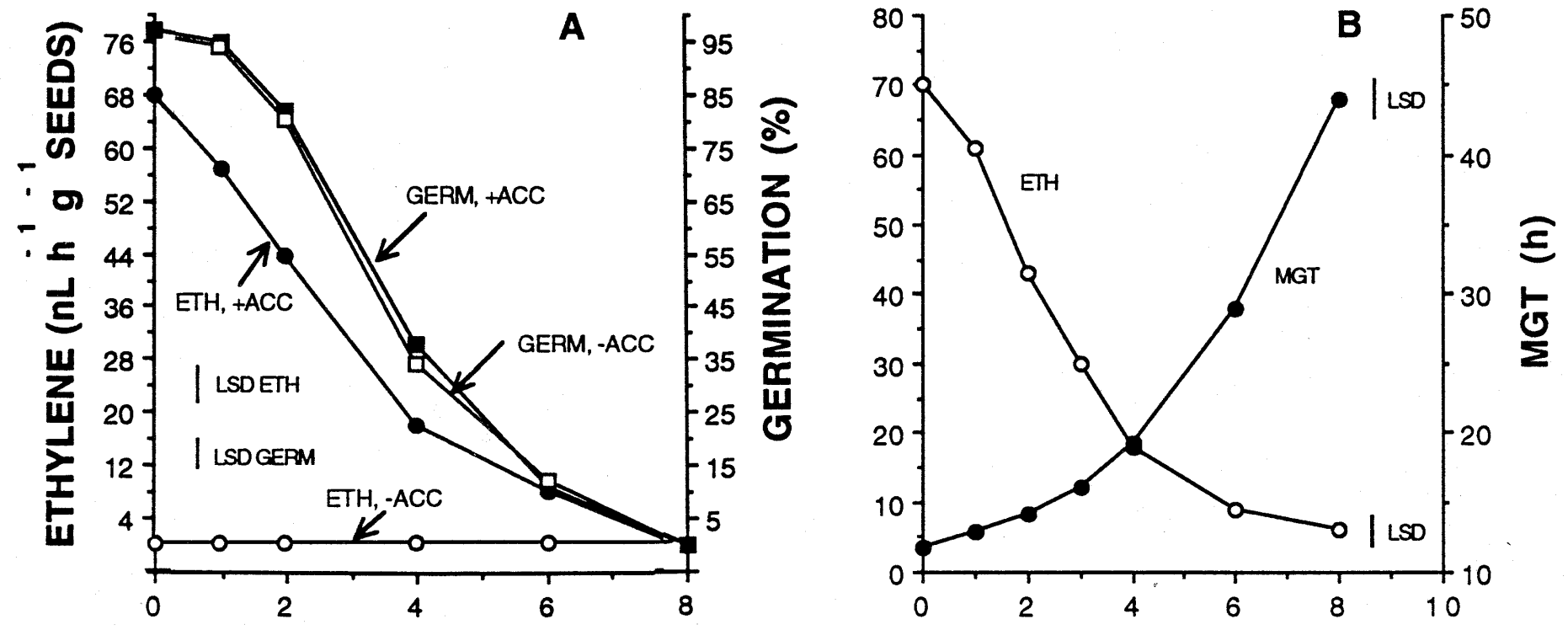

DAYS AGED

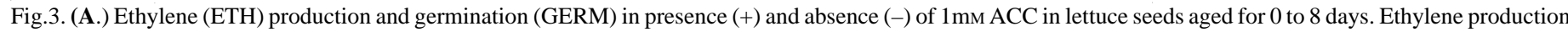

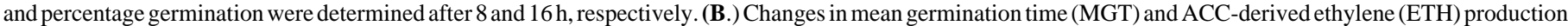

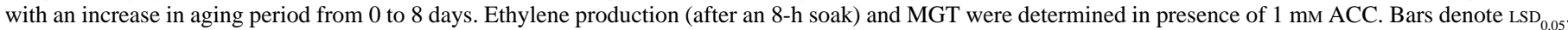




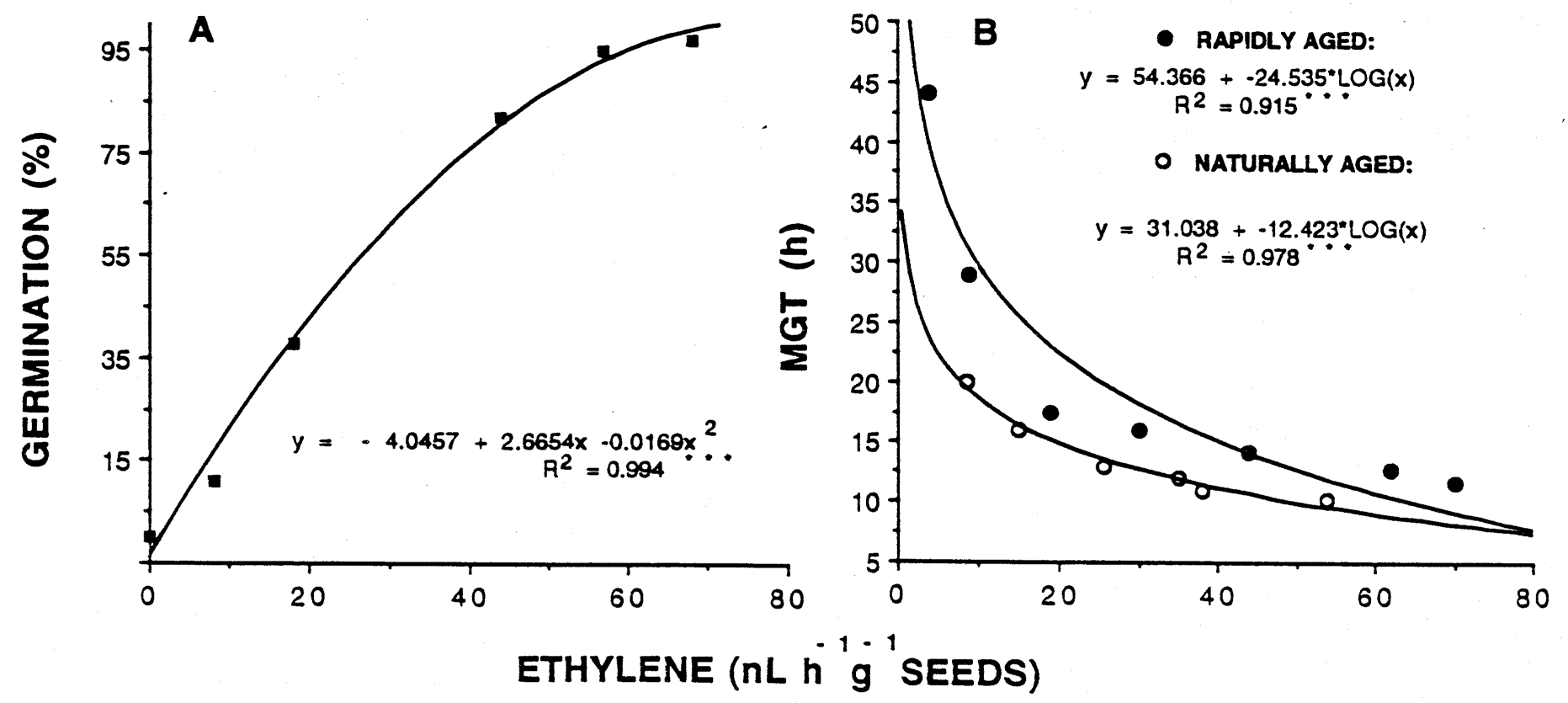

Fig. 4. (A.) Quadratic response of ACC-derived ethylene production and germination of six aged-lettuce seed lots. Ethylene and germination data are from seeds soaked in $1 \mathrm{~mm}$ ACC for 8 and $16 \mathrm{~h}$, respectively (see Fig. 3A). (B.) Logarithmic response of ACC-derived ethylene production and mean germination time (MGT) of lettuce seed lots, aged rapidly and naturally (see Materials and Methods) for various periods. Ethylene production and MGT values are from rapidly aged and from naturally aged seeds soaked in $1 \mathrm{~mm}$ ACC. ${ }^{* * *}$ Significant at $P=0.05$.
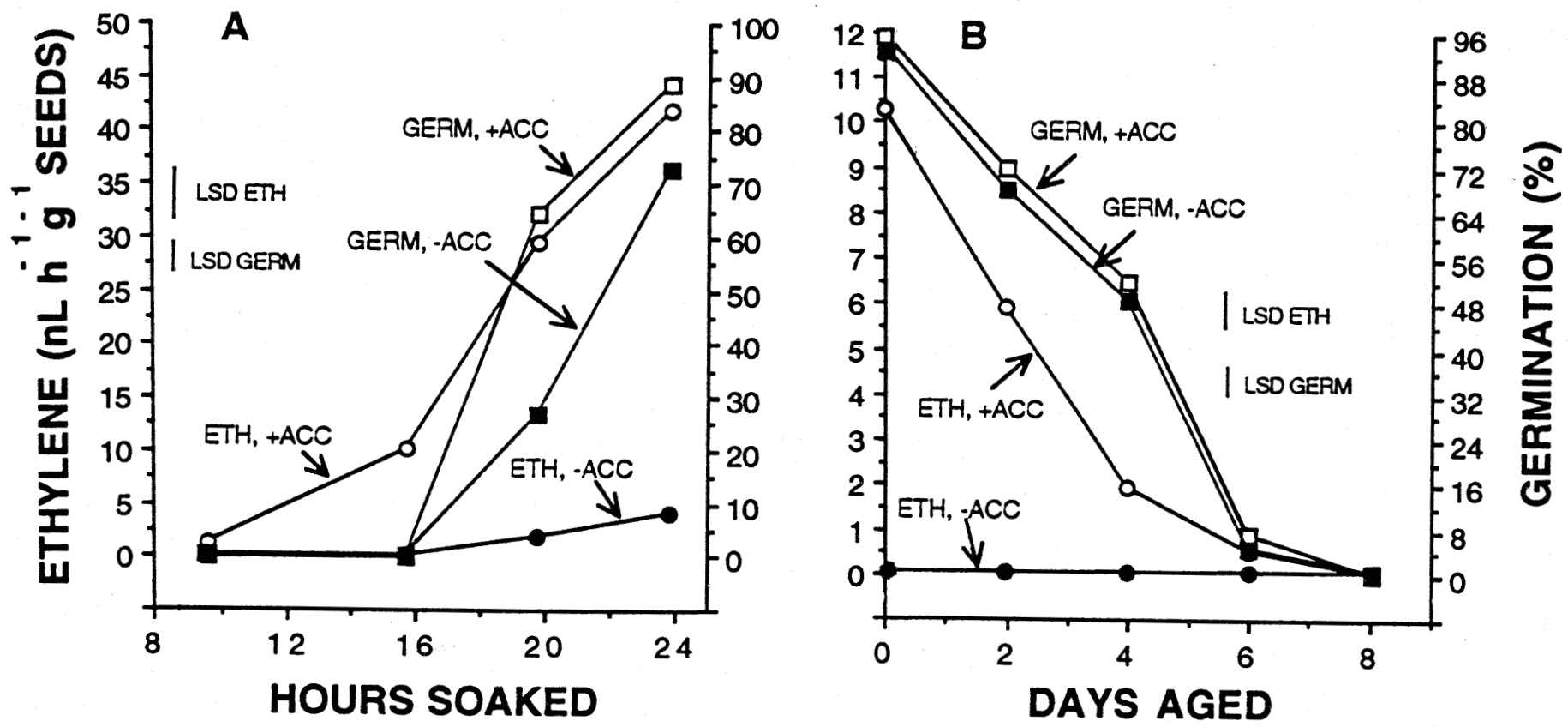

Fig. 5. (A.) Time course of ethylene (ETH) production and germination (GERM) in cabbage seeds soaked in presence (+) and absence (-) of $1 \mathrm{~mm}$ ACC. (B.) Ethylene $($ ETH) production and germination (GERM) in presence $(+)$ and absence $(-)$ of $1 \mathrm{~mm}$ ACC in cabbage seeds aged for 0 to 8 days. Ethylene production and percentage germination were determined after 16- and 24-h soaks, respectively. Bars denote LSD $_{0.05}$.

during soaking of up to $48 \mathrm{~h}$, even though germination occurred at $30 \mathrm{~h}$ (Fig. 11A). Upon addition of $2 \mathrm{~mm}$ ACC (a saturating dose), however, seeds produced detectable levels of ethylene at $8 \mathrm{~h}$ of soaking. Germination was not affected by ACC. Ethylene production and germination decreased in parallel with increased aging (Fig. 11B). A quadratic equation provided an excellent fit for the curvilinear relationship of ethylene production to germination (Fig. 12).

\section{Discussion}

These studies show that the enhanced amounts of ethylene produced by including ACC in the soak medium provide an effective means to measure vigor in diverse seed types. Soaking seeds in ACC solution may have several advantages over seeds soaked in water: 1) Application of ACC increased the ethylene produced by the seeds several times over seeds soaked in water, 
thus greatly enhancing the sensitivity of the test; 2) as large amounts of ethylene were produced, a much smaller seed sample could be used for ethylene determination; 3) the use of ACC may permit extending the range of ethylene detection to seeds having extremely low vigor; and 4) ethylene detection before germination permits the use of morphologically uniform seed samples.

In the non-ACC ethylene procedure, ethylene is generally measured at the time of or following radicle protrusion because little or no ethylene is produced before germination. Relatively large amounts of ethylene are produced at the time of radicle protrusion in seeds such as lettuce and snap bean, and, as all seeds (even in the same vigor class) do not germinate at the same rate, large sampling error (samples may differ in number of germinated

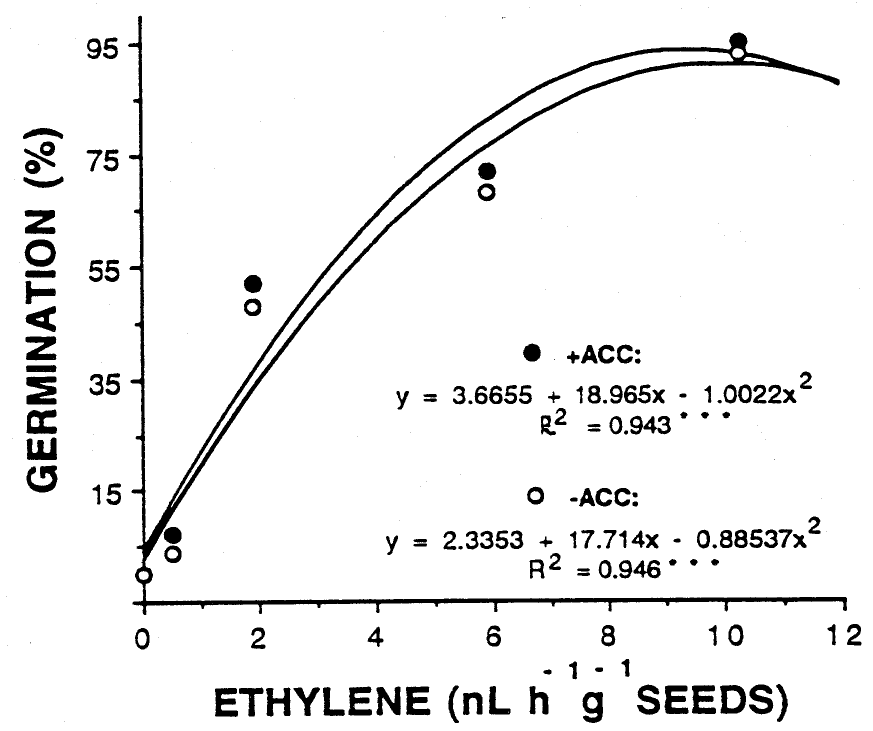

Fig. 6. Relationship of ACC-derived ethylene production to germination percentages in five cabbage seed lots aged for varying periods. Ethylene production rates in $1 \mathrm{~mm}$ ACC were regressed against germination percentages of seeds in both the presence (+) and absence of $1 \mathrm{~mm} \mathrm{ACC}$. ${ }^{* * *}$ Significant at $P=0.5$.

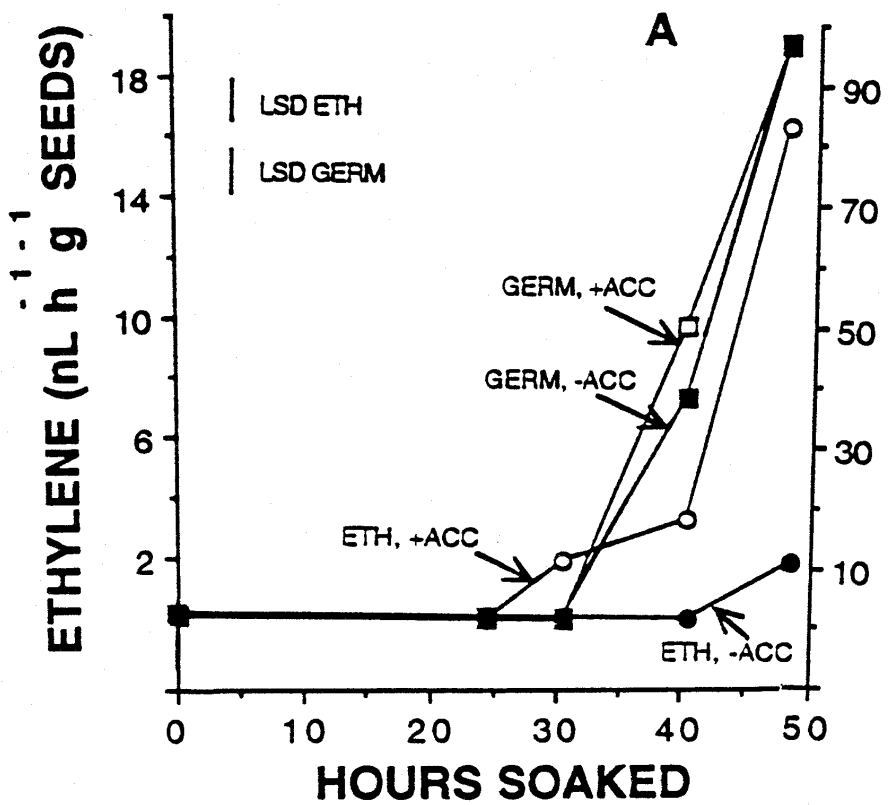

seeds and hence ethylene produced) may occur in ethylene determination. Measuring ethylene after germination may have another problem. Seeds of differing vigor germinate at differing rates requiring ethylene determination at different times and over a long period. The MGT of lettuce seeds, for example, with seven different vigor levels, ranged from 11 to $45 \mathrm{~h}$ (Fig. 3B).

$\mathrm{ACC}$ in the range of 0.25 to $2 \mathrm{~mm}$ produced maximal amounts of ethylene in the seeds tested (saturation curve shown only for lettuce). Seeds of different species differed greatly in their ability

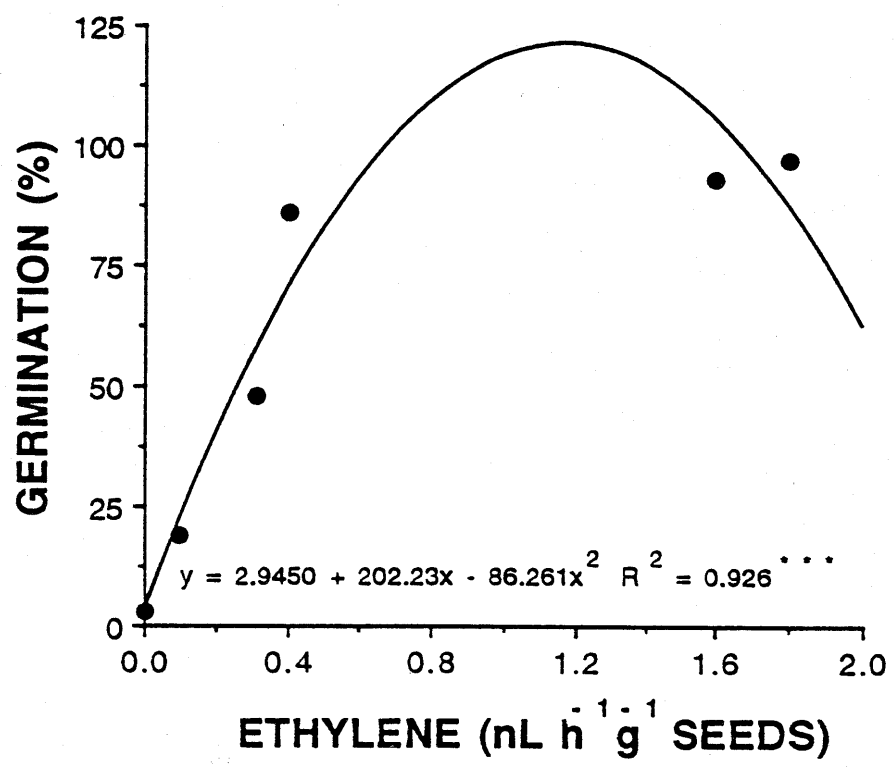

Fig. 7. (A.) Time course of ethylene $(\mathrm{ETH})$ production and germination (GERM) in tomato seeds soaked in presence $(+)$ and absence $(-)$ of $1 \mathrm{~mm}$ ACC. $($ B. Ethylene $(\mathrm{ETH})$ production and germination (GERM) in presence $(+)$ and absence (-) of $1 \mathrm{~mm}$ ACC in tomato seeds aged for 0 to 14 days. Ethylene production and germination were determined after 30 - and 48 -h soaks, respectively. Bars denote LSD $_{0.05}$.

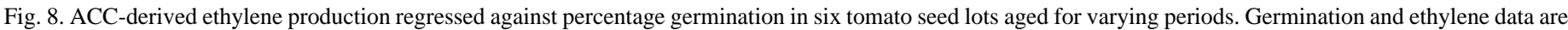
from seeds soaked in presence of $1 \mathrm{~mm}$ ACC (see Fig. 7B). ***Significant at $P=0.05$. 


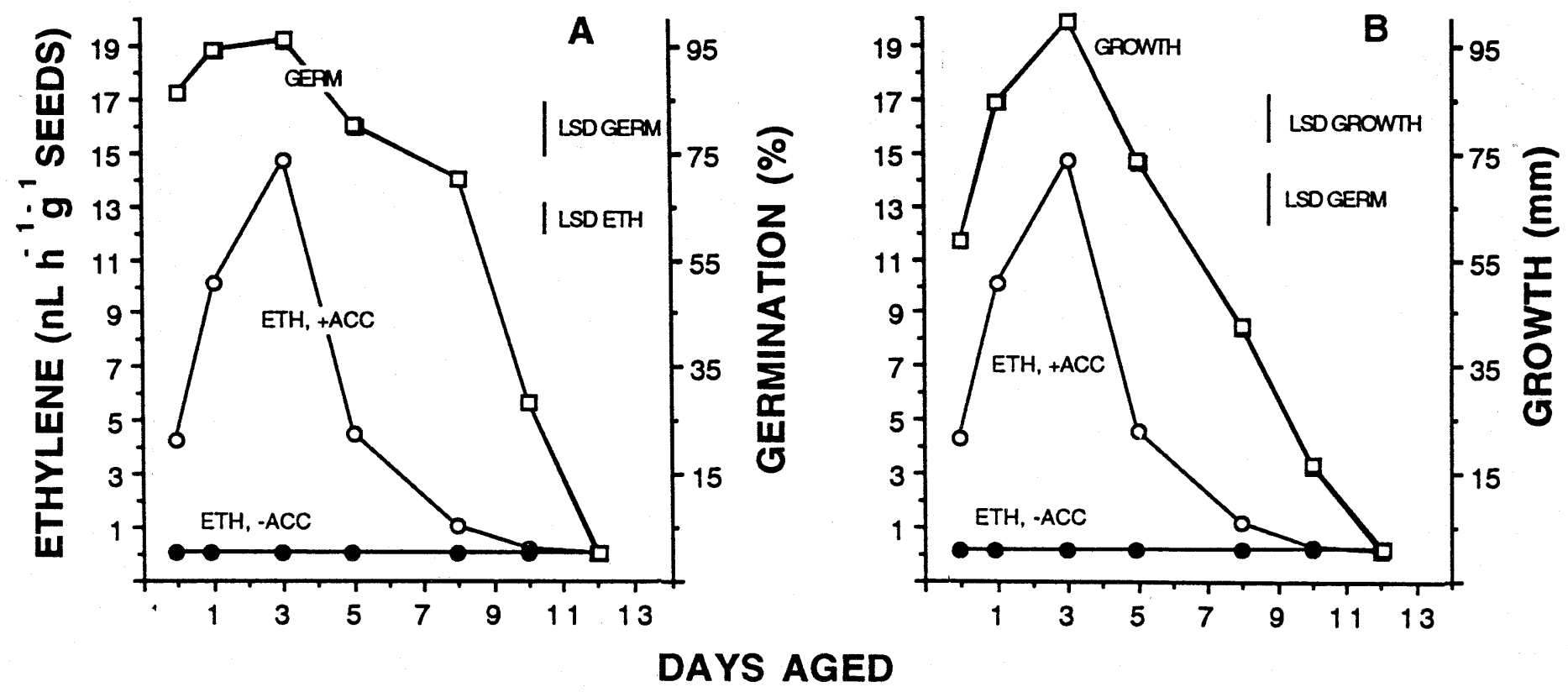

Fig. 9. (A) Ethylene (ETH) production and germination (GERM) in snap bean seeds aged for 0 to 12 days. Ethylene production was determined in the presence and absence of $1 \mathrm{~mm}$ ACC at $10 \mathrm{~h}$ of soaking and germination in the absence of ACC after $90 \mathrm{~h}$ of soaking. (B) Same as A, except seedling length determined in the absence of ACC after $90 \mathrm{~h}$ of soaking. Bars denote $\mathrm{LSD}_{0.05}$.

to convert ACC to ethylene. The amounts of ACC-derived ethylene produced at the time of germination by $1 \mathrm{~g}$ lettuce, cabbage, tomato, snap bean, and sweet corn seeds were $350,35,4,68$, and $30 \mathrm{nl} \cdot \mathrm{h}^{-1}$, respectively. Corresponding values for ethylene produced in the absence of ACC were 4, 0, 0, 2, and $0 \mathrm{nl} \cdot \mathrm{h}^{-1}$. In seeds and plant tissues, ACC is the immediate precursor of ethylene and conversion of ACC to ethylene is catalyzed by EFE, an oxygenrequiring enzyme (Yang, 1985). Aside from the genotypic differences influencing ACC conversion to ethylene, various environmental factors, such as high temperature, salinity, water stress, and seed coat restraint may also influence the ACC-to-ethylene conversion step (Khan and Huang, 1988; Khan and Prusinski, 1989). Slitting the seed coats clearly enhanced the conversion of ACC to ethylene, indicating that seed coats exert a strong barrier to oxygen penetration and optimal functioning of the EFE.

Seed vigor paralleled ACC-derived ethylene production in the seeds tested. A second-degree polynomial equation generated for the relationship of ethylene production to percentage germination (in lettuce, cabbage, tomato, snap bean, and sweet corn seeds) or seedling growth (in snap bean) provided good to excellent fit $\left(R^{2}\right.$ $=0.78$ to 0.99 ) (Fig. 4A, 6, 8, 10, 12). The upward curvilinear response was caused by germination percentage or seedling growth increasing at a decreasing rate with an increase in ethylene production. Mean germination time was also correlated with ACCderived ethylene. A logarithmic equation generated for the relationship of ethylene production to MGT in rapidly and naturally aged lettuce seeds, of differing vigor levels, provided an excellent fit $\left(R^{2}>0.9\right)$ (Fig. 4B). A downward curvilinear response was caused by MGT decreasing at a slower rate with an increase in ethylene production. Tomato, bean, and sweet corn seeds were invigorated (greater germination or growth response than the untreated seeds) somewhat during initial (1 to 3 days) exposure to high temperature and high RH used for rapid aging, while others (lettuce and cabbage seeds) were relatively less influenced. It is quite possible that the relationship of seed vigor loss and seed invigoration to ethylene may differ and may have resulted in the curvilinear response observed.
These data indicate that the activity of the enzyme (EFE), controlling ACC conversion to ethylene, declines as a result of aging and the loss in activity increases at about the midpoint of seed aging, resulting in a rapid decline in ethylene production and germination or growth. The factors controlling the rapid decline are not known. This pattern may be symptomatic of general cellular disorganization, including loss in membrane integrity and disfunction of macromolecules, accompanying vigor loss and deterioration. A relatively poor correlation $\left(R^{2}=0.788\right)$ between ethylene production and germination in snap bean seeds (Fig. 10) may be attributable to late germination count ( $90 \mathrm{~h}$ after soaking) that may have masked the small differences among the seed vigor

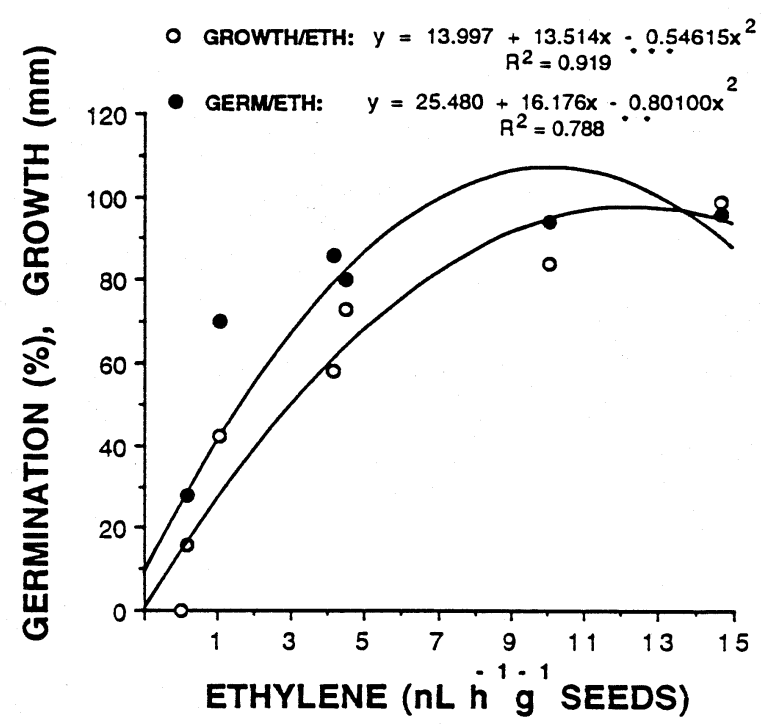

Fig. 10. Quadratic responses of ACC-derived ethylene (ETH) production against percentage germination (GERM) and growth, respectively, in six snap bean seed lots aged for varying periods. Ethylene data are from seeds soaked in $1 \mathrm{~mm}$ ACC while germination and growth data are from seeds soaked in the absence of ACC (see Fig. 9 A and B). ${ }^{* * * * * *}$ Significant at $P=0.05$ or 0.005 , respectively. 
classes. The loss of $\alpha$-amylase activity (VanOnckelen et al., 1974), degradation of ribosomes and ribosomal RNA (Osborne et al., 1974; VanOnckelen et al., 1974), and loss in membrane integrity (Matthews and Bradnock, 1968) have been associated with loss in seed vigor.

A highly sensitive seed-vigor test based on the conversion of ACC to ethylene has been described. The test is applicable to a large number of seeds. The procedure is rapid, requires relatively small number of seeds, is highly reproducible, and permits detection of ethylene before germination. The ACC-ethylene test can be used to monitor small changes in vigor levels of seeds in storage and to predict seed performance.

\section{Literature Cited}

Association of Official Seed Analysts. 1993. Seed vigor testing handbook. Assn. Offic. Seed Anal., Lincoln, Neb.

Byrd, H.W. and J.C. Delouche. 1971. Deterioration of soybean seed in storage. Proc. Assn. Offic. Seed Anal. 61:41-57.

Ching, T.M. 1982. Adenosine triphosphate and seed vigor, p. 487-506. In: A.A. Khan (ed.). The physiology and biochemistry of seed development, dormancy and germination. Elsevier Biomedical Press, Amsterdam. Clark, B.E. 1954. Factors affecting the germination of sweet corn in low temperature laboratory tests. N.Y. State Agr. Expt. Sta. Bul. 769:1-24.

Gorecki, R.J., H. Ashino, S. Satoh, and Y. Esashi. 1991. Ethylene production in pea and cocklebur seeds of differing vigor. J. Expt. Bot. 42:407-414.

Harman, G.E., B.L. Nedrow, B.E. Clark, and L.R. Mattick. 1982. Association of volatile aldehyde production during germination with poor soybean and pea seed quality. Crop Sci. 22:712-716.

Khan, A.A., M. Akbar, and D.V. Seshu. 1987. Ethylene as an indicator of salt tolerance in rice. Crop Sci. 27:1242-1247.

Khan, A.A. and X.-L. Huang. 1988. Synergistic enhancement of ethylene production and germination with kinetin and 1-aminocyclopropane-1carboxylic acid in lettuce seeds exposed to salinity stress. Plant Physiol. 87:8476-852.

Khan, A.A. and J. Prusinski. 1989. Kinetin enhanced 1-aminocyclopropane1-carboxylic acid utilization during alleviation of high temperature stress in lettuce seeds. Plant Physiol. 91:733-737.

Khan, A.A. and D.V. Seshu. 1987. Using ethylene to monitor the influence of adverse climatic factors and to predict plant performance, $\mathrm{p}$. 103-122. Proc. Intl. Workshop on the Impact of Weather Parameters on Growth and Yield of Rice. Intl. Rice Res. Inst., Los Banos, Philippines. Moore, R.P. 1976. Tetrazolium seed testing developments in North America. J. Seed Technol. 1:17-30.

Matthews, S. and W.T. Bradnock. 1968. Relationship between seed exudation and field emergence in peas and French beans. Hort. Res. 8:89-93.

Osborne, D.J., R. Sharon, P.I. Payne, and S.P. Sen. 1974. Protein synthesis and viability in rye embryos. Bul. Royal Soc. New Zealand 12:805-812. Prusinski, J. and A.A. Khan. 1990. Relationship of ethylene production to

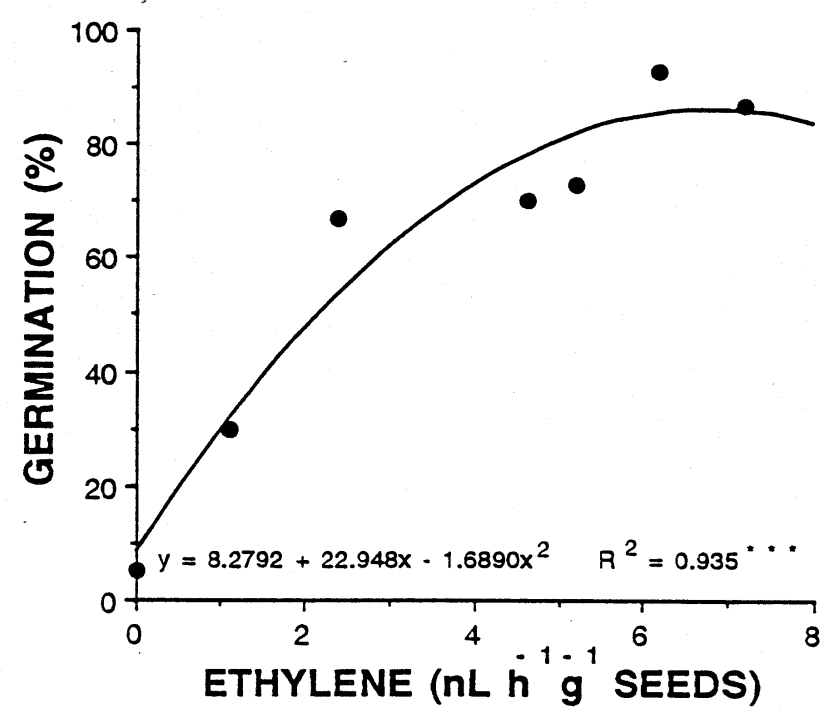

Fig. 12. ACC-derived ethylene production regressed against percentage germination in seven sweet corn seed lots aged for different periods. Ethylene and germination values are from seeds soaked in presence of $2 \mathrm{~mm}$ ACC (see Fig. 11B). **** Significant at $P=0.05$.
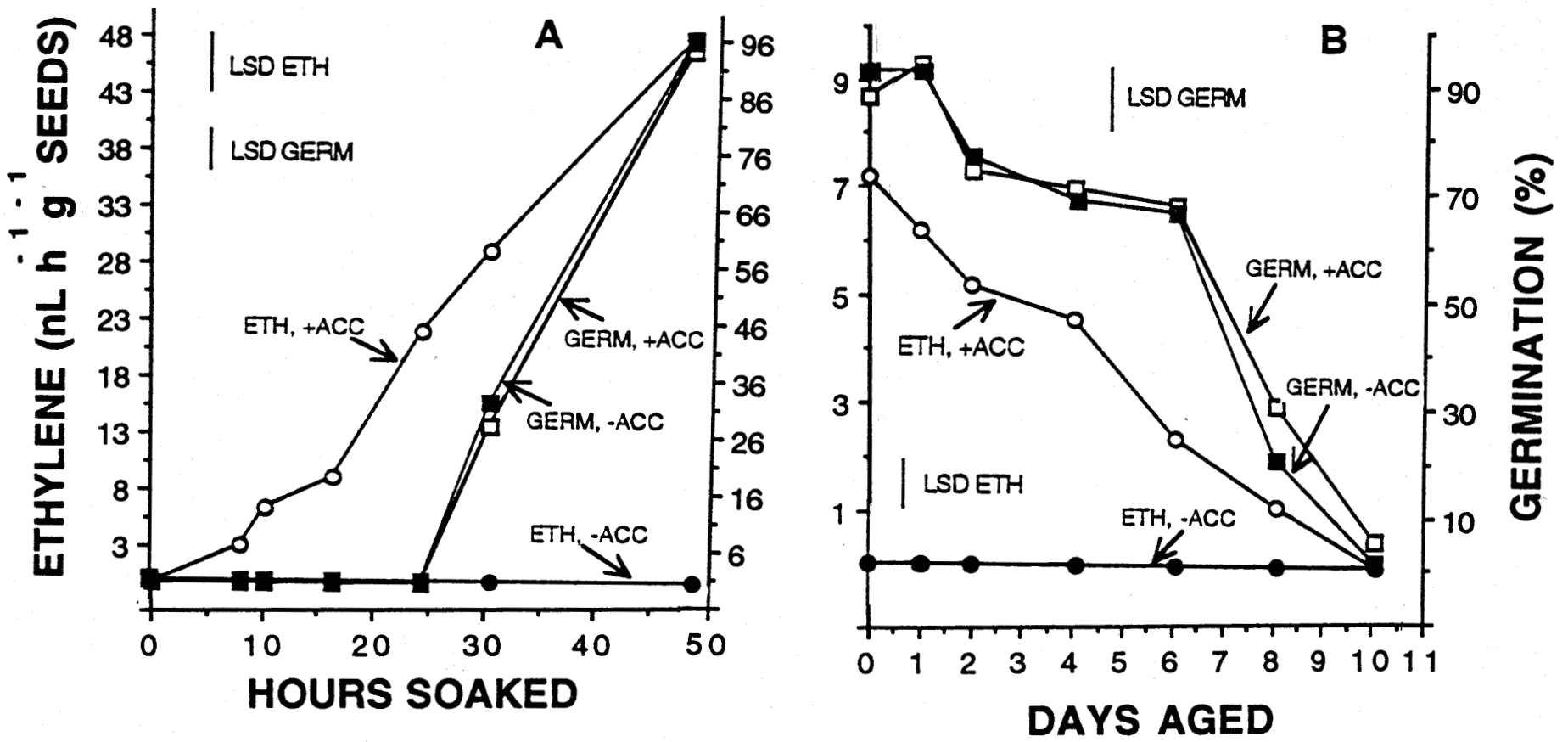

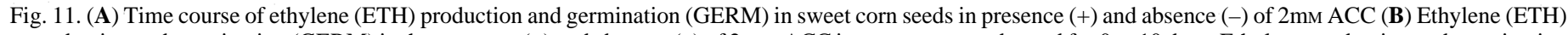

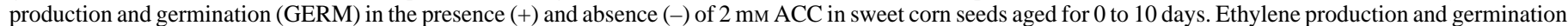
were determined after 10 and $48 \mathrm{~h}$ of soaking, respectively. Bars denote $\operatorname{LSD}_{0.05}$. 
stress alleviation in seeds of lettuce cultivars. J. Amer. Soc. Hort. Sci. 115:294-298.

Roberts, B.E., P.I. Payne, and D.J. Osborne. 1973. Protein synthesis and the viability of rye grains. Loss of activity of protein synthesizing systems in vitro associated with loss of viability. Biochem. J. 1312:275286.

Samimy, C. and A.G. Taylor. 1983. Influence of seed quality on ethylene production of germinating snap bean seeds. J. Amer. Soc. Hort. Sci. 108:767-769.

SAS. 1985. Statistical analysis systems package for personal computers. version 6. vol. 4. SAS Inst., Cary, N.C.

Takayanagi, K. and J.F. Harrington. 1971. Enhancement of germination rate of aged seeds by ethylene. Plant Physiol. 47:521-524.

Toole, E. H., V.K. Toole, and E.A. Gorman. 1948. Vegetable seed storage as affected by temperature and relative humidity. U.S. Dept. Agr. Tech. Bul. 972:1-24.

VanOnckelen, H.A, R. Verbeek, and A.A. Khan. 1974. Relationship of ribonucleic acid metabolism in embryo and aleurone to $\alpha$-amylase synthesis in barley. Plant Physiol. 53:562-568.

Woodstock, L.W. and R.B. Taylorson. 1981. Ethanol and acetaldehyde in imbibing soybean seeds in relation to deterioration. Plant Physiol. 67:424-428.

Yang, S. 1985. Biosynthesis and action of ethylene. HortScience 20:4145. 